\title{
Moderating role of locus of control over health belief model: a study of horticulturists' protective behavior
}

\author{
Roya Karami ${ }^{1} \cdot$ Nasrin Ahmadi ${ }^{1}$
}

Accepted: 15 February 2022

๑) The Author(s), under exclusive licence to Springer Science+Business Media, LLC, part of Springer Nature 2022

\begin{abstract}
The widespread prevalence of using chemical substances such as fertilizers and pesticides in garden threatens the health of horticulturists. This study aimed to investigate the underlying elements of protective behavior of horticulturists from psychological aspects. The health Belief Model is the theoretical basis of this study and moderating the role of locus of control is explored over the model. The target population of study was horticulturists of Zanjan County, Iran. A questionnaire was distributed among a random sample of 293, who were selected using multi stage stratified sampling. The study results revealed that all elements of the proposed theory significantly influence the protective behavior. Furthermore, the study results confirmed the moderating effects of locus of control on the path relation between perceived profit and cues to action with protective behavior. The suggestions to improve protective behavior for individual with internal and external locus of control are presented.
\end{abstract}

\section{Highlights}

- The Health Belief Model as a model that explains why individuals do not participate in protecting their health used in this study to design educational interventions to prevent gardeners' health risks.

- The study results revealed that all elements of proposed theory include: perceived susceptibility, perceived severity, perceived benefits, perceived barriers, self-efficacy, and cues to action significantly influence the protective behavior.

- The locus of control moderated the path relation between perceived profit and cues to action with protective behavior.

- Perceived threat, which in this study was conceptualized as a person's mental belief about the chance of being susceptible to potential danger and the severity of the danger, showed a significant influence on the protective behavior of gardeners for both groups of individuals with high internal and external locus of control.

Keywords Horticulturist $\cdot$ Health belief model $\cdot$ Locus of control $\cdot$ Perceived threat $\cdot$ Perceived profit $\cdot$ Protective behavior

\section{Introduction}

Agriculture is one of the oldest and most valuable human activities, which is associated with occupational hazards, and a large part of the world's active labor force is working in this sector economically (Borisova et al., 2018). About 8.1 billion people are employed in agriculture worldwide

Roya Karami

royakarami@pnu.ac.ir; rokarami@yahoo.com

Nasrin Ahmadi

na.ahmadi81@yahoo.com

1 Department of Agriculture, Payame Noor University (PNU), Tehran P. O. Box 19395-4697, Iran
(Mubushar et al., 2019). This large number of farmers and gardeners use chemicals such as pesticides to ensure food security and to turn the wheels of industry around the world. Agrochemicals have become an essential part of commercial agriculture since the Green Revolution (Aniah et al., 2021). As a result of this, more than 2 million tons of chemicals have been consumed by farmers and agricultural cooperatives worldwide in 2018 (Ataei et al., 2021). Furthermore, approximately 5 billion Kilograms of pesticides are used annually worldwide, which can have serious effects on nontarget organisms, the food chain, biodiversity and especially human health (Fan et al., 2015). The use of pesticides is one of the common practices of controlling diseases and pests in agriculture, but is mostly at the expense of consumer health, the environment (Mehmood et al., 2021; Mengistie et al., 
2017) and an immediate danger to the producer (Singh et al., 2018).

The widespread prevalence of using chemical substances such as fertilizers and pesticides has resulted in high demand for agrochemicals (Aniah et al., 2021) and has caused a variety of occupational hazards (Ghanbari et al., 2018). Unsafe pesticide consumption is a noteworthy concern in agriculture sector (Berni et al., 2021). Studies show that $85 \%$ of farmers and gardeners use illegal pesticides for a variety of reasons and have learned how to use pesticides mainly through verbal communication (Yang et al., 2014). Consequences including acute and chronic poisoning, and in some cases, intentional or unintentional suicides with agricultural pesticides, especially aluminum phosphide also known as rice pellets (Bonvoisin et al., 2020), have been reported, especially in rural areas. However, effective safe methods in the use of chemical stuffs such as pesticides have been proposed and introduced. But, most farmers have poor performance when using protective equipment (Berni et al., 2021; Moradhaseli et al., 2017) or they are unaware of preventive measures they need to take (Borisova et al., 2018). Despite this, agricultural producers still eat and drink while using chemicals, incorrectly dispose of empty toxin containers, store pesticides at home, use toxins improperly and with the wrong doses, ignoring the labels, improper personal hygiene after contact with toxins and ineffective methods of washing their clothes after toxin usage (Sapbamrer \& Thammachai, 2020). Studies have shown that exposure to chemicals have led to a variety of diseases including cardiovascular disease, acute neurotoxicity and neurological disorders, cancer and allergies (Wang et al., 2018). The importance of preserving the lives of gardeners is raised in a situation where the use of chemicals as one of the most important factors threatening the health of gardeners is on the rise (Andersson \& Isgren, 2021). Furthermore, limited research has been done to discover the psychological factors affecting the health and behavior of agricultural workers in Iran (Ghiasvand Ghiasi \& Ghiasvand Ghiasi, 2017).

The health of gardeners depends on protective behaviors. Protective behavior refers to a set of actions that a person takes to protect themselves by using protective equipment (Damalas \& Abdollahzadeh, 2016). Personal protective equipment that reduces the risk of diseases caused to agricultural producers (Yang et al., 2014) includes: face shields, respiratory masks, safety glasses, clean and washable long sleeve clothing, hats that are protective of the eyes and face, chemically resistant boots, gloves, goggles, etc. (Sapbamrer $\&$ Thammachai, 2020). Studies showed older farmers with lower levels of education and inadequate training are more likely to use pesticides unsafely (Berni et al., 2021; Damalas \& Abdollahzadeh, 2016; Sharifzadeh et al., 2019). Most farmers do not read pesticide labels as they are illiterate or the labels are in foreign language. Even for literate farmers sometimes the labels are too technical and confusing (Berni et al., 2021). Furthermore, many farmers and gardeners are exposed to chemicals for a long period of time and even feel the effects, but do not take the necessary precautions to reduce these effects (Ghanbari et al., 2018). Therefore, the main problem identified in this research is that gardeners do not pay sufficient attention to maintaining their health when using chemicals. This study tries to suggest related educational programs to solve the problem by examining the psychological factors affecting protective behaviors.

Although, extensive studies have been conducted on the demographic variables and farm management's features affecting protective behavior (Abdollahzadeh \& Sharifzadeh, 2021), but good agricultural practices could be influenced by various psychological and social factors (Ranjbar et al., 2021). In order for agricultural producers to change the way chemicals are used, behavioral factors, as well as barriers to behavior changes, must be identified (Ghanbari et al., 2018).

\section{Theoretical Framework}

To investigate the associated factors with protective behavior of horticulturists as an extension to the health belief model has been considered. The Health Belief Model is a comprehensively accepted conceptual model that explains why individuals do not participate in protecting their health (Abdollahzadeh \& Sharifzadeh, 2021; Sadeghi et al., 2014; Ghanbari et al., 2018; Chatripour et al., 2017; Tam et al., 2021). In this model, it is assumed that the acceptance of health and safety behavior is influenced by the individual's intention to protect themselves (Kaviani et al., 2016). This model is often used to design educational interventions to prevent disease (Ataei et al., 2021) and is appropriate for interpreting the responses of individuals who, although aware of the dangers of the disease, do nothing to reduce the likelihood of becoming diseased through improper chemical usage (Bakhshayesh, 2013). Constructs of the Health belief model include: perceived susceptibility, perceived severity, perceived benefits, perceived barriers, self-efficacy and cues to action. Studies applied these constructs as independent variables influencing protective behavior (Abdollahzadeh \& Sharifzadeh, 2021; Sadeghi et al., 2014), as has been assessed in this study. The present study further contributes to the health belief model by exploring the moderation role of the locus of control over the model. Furthermore, in the moderation model, perceived susceptibility and perceived severity are conceptualized as perceived threat and perceived profit is constructed from subtracting the barriers from benefits, self-efficacy and cues to action (See Fig. 1). 
Fig. 1 Theoretical research framework

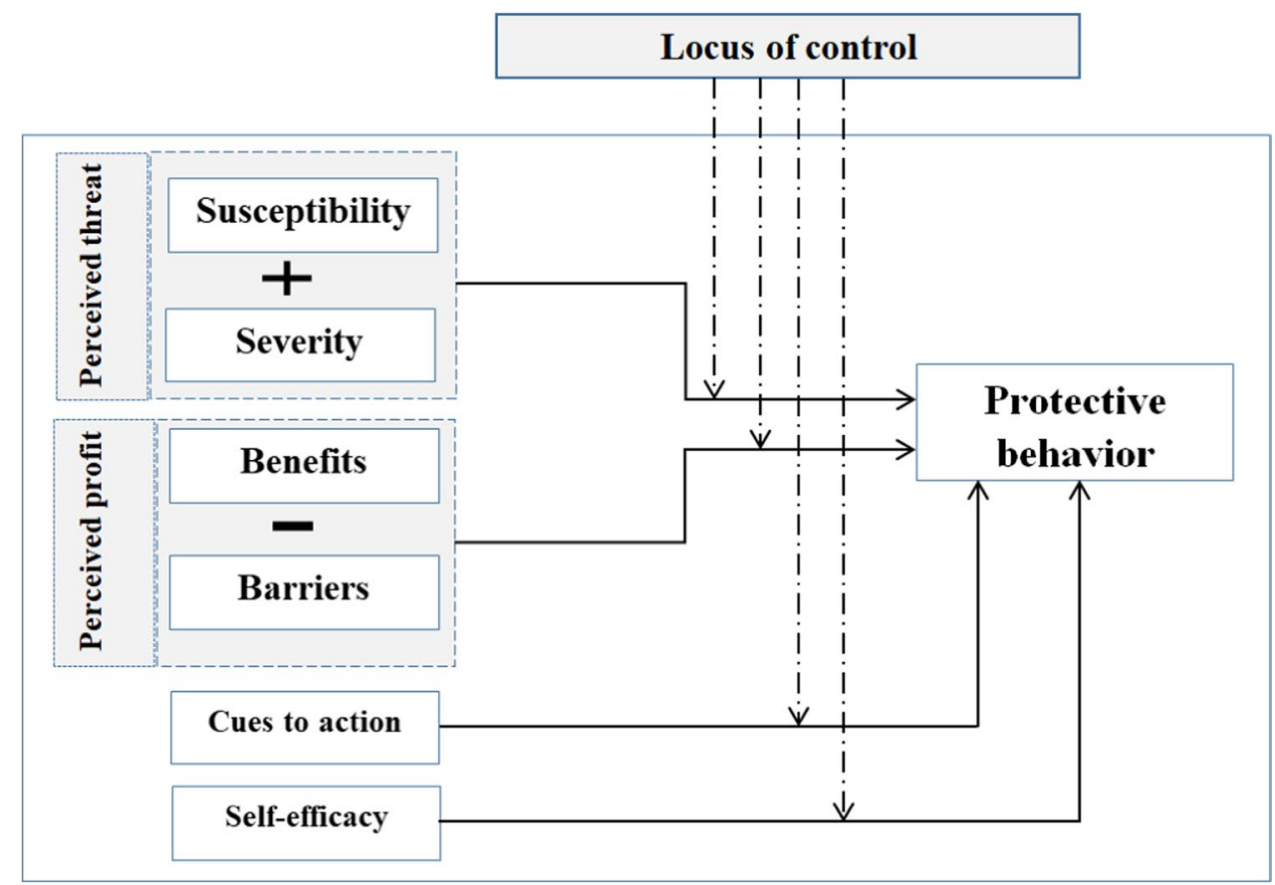

\section{Perceived Threat}

When people experience threats, their assessment regarding level of threat motivate them to involve coping behavior (Pakmehr et al., 2021). Perceived threat is a person's mental belief about the chance of being susceptible to potential danger and the severity of the danger (Azadi et al., 2019). In this study, perceived threat is made up of the sum of perceived susceptibility and perceived severity of hazards posed by unsafe use of chemicals by horticulturalists. Susceptibility means understanding the situation in which a person's health is endangered, and depends on the person's belief in how vulnerable they are (Ghanbari et al., 2018). Results of studies have shown that the higher an individual's perceived susceptibility, the more likely they are to observe protective behavior (Abdollahzadeh \& Sharifzadeh, 2021; Azadi et al., 2019; Stangier et al., 2021). Perceived severity is the belief in the seriousness of the risk (Kaviani et al., 2016). Understanding the hazard severity of unsafe use of chemicals in agriculture and possible related diseases, makes a person more willing to take suitable safety measures (Berni et al., 2021).

\section{Perceived Profit}

Profit is an economic term that is used in various fields of study. In non-economic studies it is calculated based on one's perception of the value of benefits weighed against the costs or barriers (Hongjun et al., 2015; Song et al., 2018). Perceived benefits indicate the individual's belief regarding the probability reward from partaking in preventative measures to reduce imminent threat (Mirzaei et al., 2017). At this stage, after threat appraisal, the individual realizes the benefit and the barrier of preventive behavior (Sapbamrer \& Thammachai, 2020). Perceived barriers refer to the consequences that human beings experience when using protective measures and are inversely related to protective behaviors (Ataei et al., 2021). Perceived barriers of protective behavior include: psychological barriers such as lack of popularity by neighboring farmers (Sapbamrer \& Thammachai, 2020); technical barriers such as reduced physical flexibility, heat stress, extra time required (Abdollahzadeh \& Sharifzadeh, 2021) and economical barriers such as increased costs (Berni et al., 2021). Therefore, in the present study, perceived benefits of implementing protective behaviors considered as value, and perceived barriers consider as the cost of obtaining that value. In order to calculate the perceived profit, the perceived costs (including time, financial, psychological and technical costs) is deducted from the perceived value of the benefits of implementing protective behavior (which consists of the value of reducing occupational hazards, and ensuring health to the gardeners).

\section{Self-efficacy}

Self-efficacy refers to an individual's trust and belief in their ability to perform tasks optimally (Azadi et al., 2019). Self-efficacy in protective behavior is related to the individual's belief that they can successfully protect themselves by using protective equipment (Ataei et al., 2021; Kaviani et al., 2016). Self-efficacy is a significant contributor to farmers' coping with the problems faced (Pakmehr et al., 
2021). Azadi et al. (2019). With regard to the identification of structures affecting the adaptive behaviors of wheat farmers in Kermanshah, Iran under the conditions of climate change, positive correlation has been found between the component of self-efficacy and conservation behavior. Tam et al. (2021) showed that self-efficacy could mediate the association between stressor factors and preventive behavior. Also, Ghanbari et al. (2018) in analyzing the protective behavior of farmers in Khorramabad City, Iran, by the health belief model showed a positive relationship between selfefficacy and protective behavior.

\section{Cues to Action}

Cues to action is a guidance that stimulates appropriate behavior to maintain health and is a reminder that engages the person mentally and makes them realize the importance of using personal protective equipment and taking the necessary action (Abdollahzadeh \& Sharifzadeh, 2021). Ghanbari et al. (2018) suggests friends, neighbors, radio, television and media are examples of guiding stimuli. While another study relates this component to participating in training courses, studying educational posters and banners, reading instructions on pesticide containers, and communicating with experts and specialists as variables which affect a person's decision to perform a particular action and give them a higher motivation to use personal protective equipment (Seydi \& Rezaei, 2019). Thus, it could be interpreted that cues to action could defines as social pressure through friend and neighbors which is more related to social facets, and technical guidance.

\section{Locus of Control}

According to our investigations, no study formally has yet examined the role of locus of control into gardeners undertaking self-protective behaviors. A study has previously discussed the perceived behavioral control in influencing good agricultural practices (Ranjbar et al., 2021). The reason to explore the role of locus of control in protective behavior, is that the results of different studies show that the locus of control is a significant indicator of health behaviors (Boyd \& Wilcox, 2020; Clark et al., 2018; Conell-Price \& Jamison, 2015; Pedron et al., 2021). Furthermore, it is worthy to note whether difference in protective behavior as a health behavior is only related to self-preference or other variables which are sometimes rooted in stereotypes, which also plays a leading role (Conell-Price \& Jamison, 2015). The individual socialization process and diverse socioeconomic environments from childhood, can lead to a dissimilar belief on control over life circumstances, whereas a weaker economic background may lead to less control beliefs in life (Whitehead et al., 2016). Studies have identified the locus of control as a constructive variable of motivation (Lajunena \& Räsänen, 2004) and a mediator in explaining behavior (Pedron et al., 2021). Locus of control raised from Rotter's theory (Clark et al., 2018) and is defined as beliefs in having control over one's life outcomes. It includes two dimensions, either internal and external which capture different facets (Pedron et al., 2021). An internal locus of control refers to the belief that life outcomes are determined by an individual's own actions and therefore is controllable (Lajunena \& Räsänen, 2004; Bucciol \& Trucchi, 2021). An external locus of control refers to the belief that life outcomes are related to external factors such as fate and luck, which are beyond the individual's control (Clark et al., 2018). An active response would be due to an internal locus of control (Bucciol \& Trucchi, 2021), while, different expectations, passive or sometimes aggressive response could be the result of external locus of control (Whitehead et al., 2016).

\section{Methods}

The present study was carried out using descriptive-correlation methods using a survey design. The target population of the study comprised 6673 gardeners of Zanjan County located at Zanjan province, Iran. The number of samples was calculated according to Cochran's formula including 293 people. The sampling procedure was multi stage stratified sampling. In the first stage of sampling, out of thirteen rural district of Zanjan County, two were randomly selected. The selected rural districts were Taham and Mojezat. Then in the second stage in each rural district the villages were selected randomly and proportionally. In Taham rural district, 11 villages and 100 gardeners and in Mojezat, 19 villages and 193 gardeners were randomly selected. The data were collected using a questionnaire. The questionnaire with structured items surveyed the characteristics of the gardeners (age, work experience, educational level, and garden area per hectare) and included six more parts:

1. Protective behavior measured in terms of using face shield, respiratory mask, safety glasses, clean and washable long sleeve clothing, eye and face protective hat, chemical resistant boots, gloves and goggles by 8 items adopted from Sapbamrer and Thammachai (2020).

2. Perceived threat investigated through 6 items of perceived susceptibility and 4 items of perceived severity adopted from Abdollahzadeh and Sharifzadeh (2021). To measure the perceived susceptibility, gardener's belief in vulnerability to unsafe use of chemicals in the garden was investigated, and to measure perceived severity, gardener's belief in the seriousness of the risk was assessed. 
3. Perceived profit assessed with 6 items of benefits and 4 items of barriers adopted from Abdollahzadeh and Sharifzadeh (2021) in which benefits questions was related to gardener's perception on the benefits of using protective equipment in reducing occupational hazards and ensuring health, and questions of perceived barriers includes reducing physical flexibility, high cost, extra time required, and lack of popularity.

4. Cues to action which is about guidance that stimulates appropriate behavior to maintain health measured using 4 items adopted from Seydi and Rezaei (2019),

5. Self-efficacy examined by means of 4 items related to the gardener's belief on their ability to successfully protect him by using protective equipment that adopted from Seydi and Rezaei (2019).

6. Locus of control surveyed via 10 items using adopted version of Richter et al. (2013) and Pedron et al. (2021) including two dimensions: internal locus of control measuring the belief that human health is determined by individual own actions and external locus of control investigated in terms of gardener's belief that human health is related to destiny and luck and is out of control.

The items of question were measured, using five-point Likert-type scaling, using a questionnaire. The validity of the questionnaire has been assessed by a panel of expert and reliability has been measured and confirmed through a pilot study. In order to evaluate the reliability of questionnaire, gardeners of a village (Kushkan village) were selected, which is among the study population and is outside of the sample. The data collection was conducted in March and April of 2021 through face-to-face interviews, following necessary COVID-19 related health protocols including the use of social distancing. The data has been analyzed using Structural Equation Modeling.

\section{Results}

The results of the demographic investigation of horticulturists, deliberates that the average age of respondents was 51.7 years of age with a mean work experience of 28.6 years. The highest observed frequency regarding garden area (183 out of 293 people) was in the range of one and a half hectares or less. Regarding levels of education, $22.5 \%$ were found to be illiterate; nearly half were in the category of not having received their diploma $(42 \%)$. The protective behavior of horticulturists against diseases related to chemical use was investigated in terms of wearing mask, goggles, hat, gloves, boots, respirator, coveralls, clean and washable long sleeve clothing. The results revealed that almost half of the respondents $(53.9 \%)$ have an intermediate level of engagement in protective behaviors, neither systematic safe behavior nor vice versa. Nearly a quarter $(22.2 \%)$ had the potential to protect them using protective equipment if guided. Only $5.2 \%$ of respondents reported that they protect themselves safely while using chemicals in gardening.

\section{Measurement Model Testing}

The result of measurement model assessment based on the GOF indices indicates a relative good fit between the data and the proposed model; $\left[\chi^{2}(573)=709.410, p=.000 ; \chi^{2 /}\right.$ $\mathrm{df}=1.238 ; \mathrm{GFI}=.887 ; \mathrm{CFI}=.980 ; \mathrm{NFI}=.905 ; \mathrm{IFI}=.980 ;$ $\mathrm{TLI}=.978$; RMSEA $=.029]$. The CFI, NFI, IFI and TLI significantly pass its cutoff value of .90 (Hair et al., 2010; Ho, 2006). In addition to this, the RMSEA was .029, which was less than the recommended value of .08 specified to provide a satisfactory fit for the proposed model.

The results of correlation estimates amongst constructs in measurement model showed that all of the correlation estimates were significantly different from zero at the 0.001 level, excluding the correlation between barriers and cues to action $(r=-0.15)$ that was significantly different from zero at the 0.05 level (Table 2). The significant correlation of all constructs with other constructs confirms the logical validity. The results of the assessed convergent validity showed that all standardized factor loadings exceed the recommended value of 0.5 and were significant at 0.001 alpha levels (Table 1). Moreover, the Average Variance Extracted (AVE) and Composite Reliability (CR) values for the entire constructs exceeded the minimum criterion of 0.5 and 0.7 respectively, ensuring satisfactory internal consistency amongst the measured items (Table 2). Discriminant validity among the constructs supported since, the AVE value for each construct were higher than those of ASV and MSV in measurement model (Table 2).

\section{Structural Model Testing}

The estimated structural model based on the set of statistical goodness of-fit indices, provided a satisfactory fit to data where, the GFI, CFI, TLI and IFI significantly pass the cut off value (0.9) and the RMSEA with a value less than 0.08 shows a strong fit (Fig. 2). According to the hypothesized structural model, exogenous variables explained 54\% of gardener's protective behavior variance. Moreover, the result demonstrated that self-efficacy $(\beta=.235, \mathrm{C} . \mathrm{R}=4.107$, $p=.000)$; perceived threat $(\beta=.385, \mathrm{C} . \mathrm{R}=6.559, p=.000)$; perceived profit $(\beta=.198, \mathrm{C} . \mathrm{R}=3.837, p=.000)$; and cues to action $(\beta=.143, \mathrm{C} . \mathrm{R}=2.832, p=.005)$ had a positive significant impact on gardener's protective behavior (Fig. 2). 
Table 1 First- order CFA result (Standardized factor loading)

\begin{tabular}{|c|c|c|}
\hline Constructs & $\begin{array}{l}\text { Measurement } \\
\text { items }\end{array}$ & $\begin{array}{l}\text { Standardized } \\
\text { factor loading* } \\
\text { (t-value) }\end{array}$ \\
\hline \multirow[t]{8}{*}{ Protective behavior } & PB1 & 0.782 (fixed) \\
\hline & PB2 & $0.845(16.175)$ \\
\hline & PB3 & $0.821(15.588)$ \\
\hline & PB4 & $0.736(13.567)$ \\
\hline & PB5 & $0.835(15.923)$ \\
\hline & PB6 & $0.793(14.901)$ \\
\hline & PB7 & $0.850(16.303)$ \\
\hline & PB8 & $0.758(14.080)$ \\
\hline \multirow[t]{6}{*}{ Susceptibility } & SU1 & 0.789 (fixed) \\
\hline & SU2 & $0.825(15.722)$ \\
\hline & SU3 & $0.803(15.194)$ \\
\hline & SU4 & $0.741(13.695)$ \\
\hline & SU5 & $0.871(16.914)$ \\
\hline & SU6 & $0.865(16.744)$ \\
\hline \multirow[t]{4}{*}{ Severity } & S1 & 0.844 (fixed) \\
\hline & S2 & $0.721(12.733)$ \\
\hline & S3 & 0.783 (13.912) \\
\hline & S4 & $0.581(9.912)$ \\
\hline \multirow[t]{4}{*}{ Benefits } & B1 & 0.863 (fixed) \\
\hline & $\mathrm{B} 2$ & $0.657(12.312)$ \\
\hline & B3 & $0.822(16.968)$ \\
\hline & B4 & $0.862(18.122)$ \\
\hline \multirow[t]{6}{*}{ Barriers } & Bar1 & 0.879 (fixed) \\
\hline & Bar2 & $0.769(16.185)$ \\
\hline & Bar3 & $0.804(17.410)$ \\
\hline & Bar4 & $0.847(19.086)$ \\
\hline & Bar5 & $0.689(13.651)$ \\
\hline & Bar6 & 0.785 (16.747) \\
\hline \multirow[t]{4}{*}{ Self-efficacy } & SE1 & 0.847 (fixed) \\
\hline & SE2 & $0.729(13.931)$ \\
\hline & SE3 & 0.768 (14.969) \\
\hline & SE4 & $0.872(17.742)$ \\
\hline \multirow[t]{4}{*}{ Cues to action } & CA1 & 0.777 (fixed) \\
\hline & $\mathrm{CA} 2$ & $0.846(14.750)$ \\
\hline & CA3 & $0.761(13.196)$ \\
\hline & CA4 & $0.819(14.305)$ \\
\hline
\end{tabular}

*all factor loading is significantly different from zero at the 0.001 level

\section{Moderator Effects of Locus of Control Testing}

To investigate the locus of control moderator effect on the relation model between the variables of the health belief theory and gardeners' protective behavior, a multi-group modeling test using Amos software conducted. Firstly, separate but identical path models for the internal (Fig. 3a) and external (Fig. 3b) locus of control samples were set up; secondly, an invariant model (in which the relation path for respondents with higher internal or external locus of control are hypothesized to share the same regression weights) was setup as well as a variant model (in which the relation path for respondents with higher internal or external locus of control are hypothesized to have different regression weights) that can be directly compared as to their model-fit; and lastly the Critical Ratio criterion employed to assess for differences in the regression weights (Ho, 2006).

The results showed that although the chi-square values for both path models are statistically significant (i.e., both models yielded poor fit by the chi-square goodness-of-fit test), the baseline comparison fit indices (including; GFI, IFI, TLI and CFI) for variant models yielded a better value in comparison with the invariant model (Table 3). Although the RMSEA fit index, yielded a very close value for two group-variant and group-invariant models (.025 and .029 respectively), which values are deemed acceptable (Schumacker \& Lomax, 2010). In addition to this, the fit of the two competing models can be directly compared via the nested model comparisons statistics. The result of nested model comparisons specified that the chi-square difference value for the two models is 73.587, with 44 degrees of freedom, and that this value is significant at the .05 level $(p=.003$ then $p<.05$ ) (Table 3 ). Thus, the two models are different significantly in their goodness-of-fit, and the group-variant model's estimates are preferable over the group-invariant. In other words, the hypothesized structural models for gardeners with higher internal or external locus of control do not share the same regression weights.

The results showed some differences in the size and significance of path regression weights influencing gardeners' protective behavior due to moderator effects of locus of control variable (Fig. 3a, b and Table 4). The hypothesized model based on moderator effects of locus of control explained $62 \%$ of the variance in the uptake of protective behaviors for respondents with higher internal locus of control (Fig. 3a) which is higher than the explained variance for respondents with higher external locus of control (52\%) (Fig. 3b), as well as slightly higher than explained variance for main hypothesized structural model (54\%) (Fig. 2).

The result showed that the path relation between selfefficacy and protective behavior for respondents with higher internal $(\beta=.272, \mathrm{C} . \mathrm{R}=3.502, p=.015)$ and external $(\beta=.211, C . R=2.609, p=.009)$ locus of control were significant (Table 4$)$. The result demonstrated that the perceived threat had linear positive effects on protective behavior of gardener with higher internal $(\beta=.383, C . R=4.691$, $p=.000)$ and external $(\beta=.324, \mathrm{C} . \mathrm{R}=3.932, p=.000)$ locus of control. Furthermore, the result indicated that perceived profit had a significant impact on protective behavior for respondent with higher internal locus of control $(\beta=.279$, $\mathrm{C} . \mathrm{R}=3.682, p=.000$ ), whereas this path was non-significant for respondent with high external locus of control $(\beta=.102$, 
Table 2 Summary of measurement model including correlation, validity and reliability statistics

\begin{tabular}{|c|c|c|c|c|c|c|c|c|c|c|c|}
\hline \multirow[t]{2}{*}{ Constructs } & \multirow[t]{2}{*}{ AVE } & \multirow[t]{2}{*}{$\mathrm{CR}$} & \multirow[t]{2}{*}{ ASV } & \multirow[t]{2}{*}{ MSV } & \multicolumn{7}{|c|}{ Correlation } \\
\hline & & & & & 1 & 2 & 3 & 4 & 5 & 6 & 7 \\
\hline 1.Protective behavior & 0.64 & 0.918 & .26 & .53 & 1 & & & & & & \\
\hline 2. Susceptibility & 0.66 & 0.92 & .22 & .53 & $0.73 * * *$ & 1 & & & & & \\
\hline 3. Severity & 0.54 & 0.82 & .16 & .28 & $0.44 * * *$ & $0.43 * * *$ & 1 & & & & \\
\hline 4. Benefits & 0.65 & 0.88 & .15 & .28 & $0.46 * * *$ & $0.35 * * *$ & $0.53 * * *$ & 1 & & & \\
\hline 5. Barriers & 0.63 & 0.91 & .07 & .15 & $-0.39 * * *$ & $-0.26 * * *$ & $-0.27 * * *$ & $-0.24 * * *$ & 1 & & \\
\hline 6. Self-efficacy & 0.65 & 0.88 & .17 & .30 & $0.55 * * *$ & $0.55 * * *$ & $0.36 * * *$ & $0.44 * * *$ & $-0.22 * * *$ & 1 & \\
\hline 7. Cues to action & 0.64 & 0.87 & .08 & .15 & $0.38 * * *$ & $0.36 * * *$ & $0.29 * * *$ & $0.20 * *$ & $-0.15^{*}$ & $0.23 * * *$ & 1 \\
\hline
\end{tabular}

Correlation significance: $* * * p<0.001,{ }^{*} p<0.05$

Fig. 2. significance testing results of the main structural model path coefficient (all path were significance: $p<0.01$ )

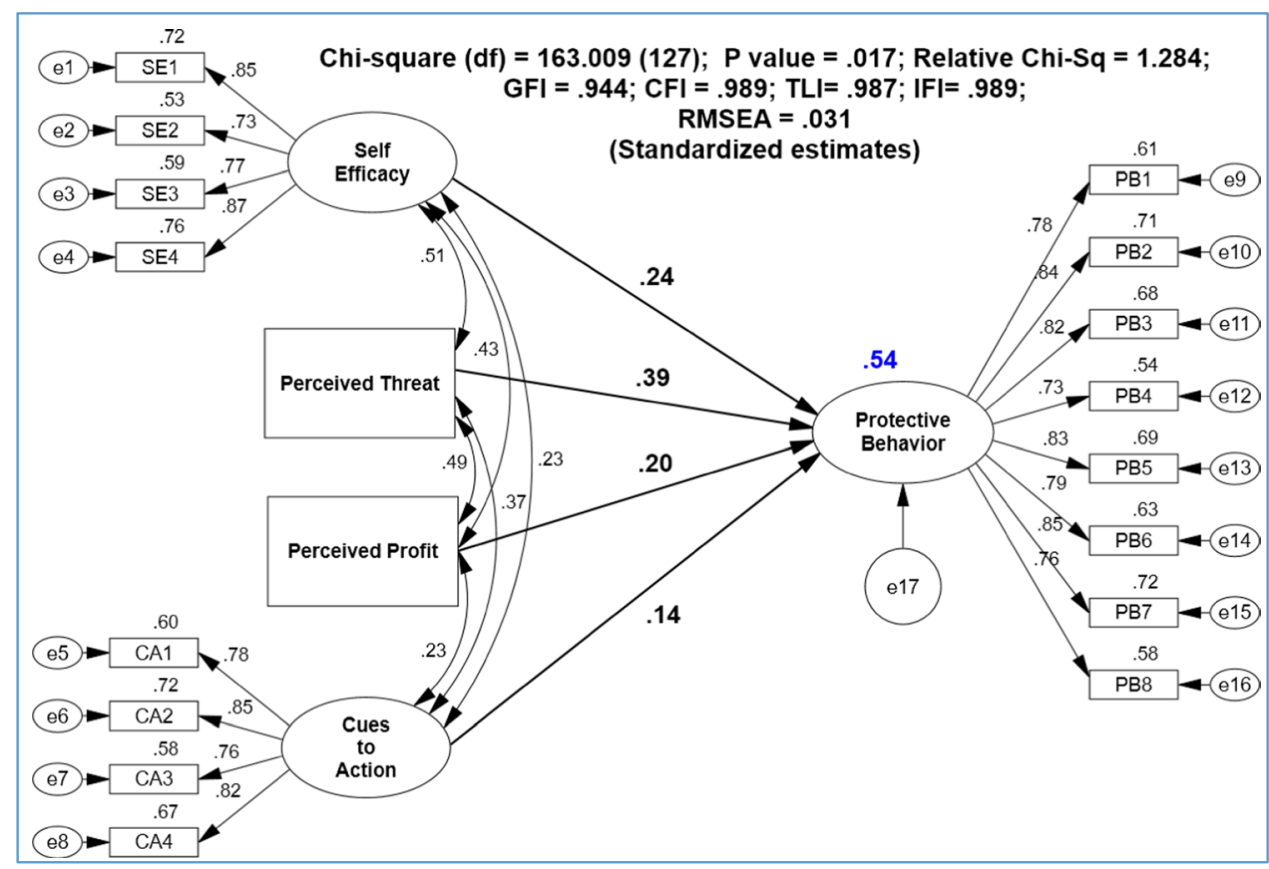

C. $\mathrm{R}=1.461, p=.144$ ) (Table 4). Furthermore, the result showed that the cues to action had linear positive effects on protective behavior of gardener with higher external locus of control $(\beta=.303, \mathrm{C} . \mathrm{R}=3.687, p=.000)$, while this path relation was non-significant for respondent with high internal locus of control $(\beta=.038, \mathrm{C} . \mathrm{R}=.601, p=.548)$ (Table 4$)$.

The Critical Ratios (C.R.) have comparison pairs for the differences between the parameters shown in Table 4, indicated the two paths comprised of; cues to action (C.R. $=2.41> \pm 1.96)$ and perceived profit $($ C.R. $=1.97> \pm 1.96)$ to protective behavior path pairwise comparisons for higher internal and external locus of control were significant, whereas the other path pairwise comparisons included; self-efficacy (C.R. $=0.73< \pm 1.96)$ and perceived threat $($ C.R. $=-1.07< \pm 1.96)$ to protective behavior were non-significant (Table 4). Thus, these results confirmed the locus of control has moderate effects on the path relation between perceived profit and cues to action with protective behavior.

\section{Discussion and Conclusion}

This research provides insights into the predictors of Iranian horticulturists' protective behavioral measures regarding the use of chemicals whilst gardening. The measurement model findings indicated that the elements of the health belief model including perceived susceptibility, perceived severity, perceived benefits, self-efficacy and cues to action have a significant positive role in explaining protective behavior and the negative impacts of perceived barriers were also supported. These results further add to the success of the health belief model in explaining protective behaviors and were in line with studies that used this model to explain 
Fig. 3 a Locus of Control moderation structural model significance testing results (Internal Locus of control). b Locus of Control moderation structural model significance testing results (External Locus of control)
Table 3 Summary of fit indices and nested model comparisons for higher internal or external locus of control group variant and group invariant
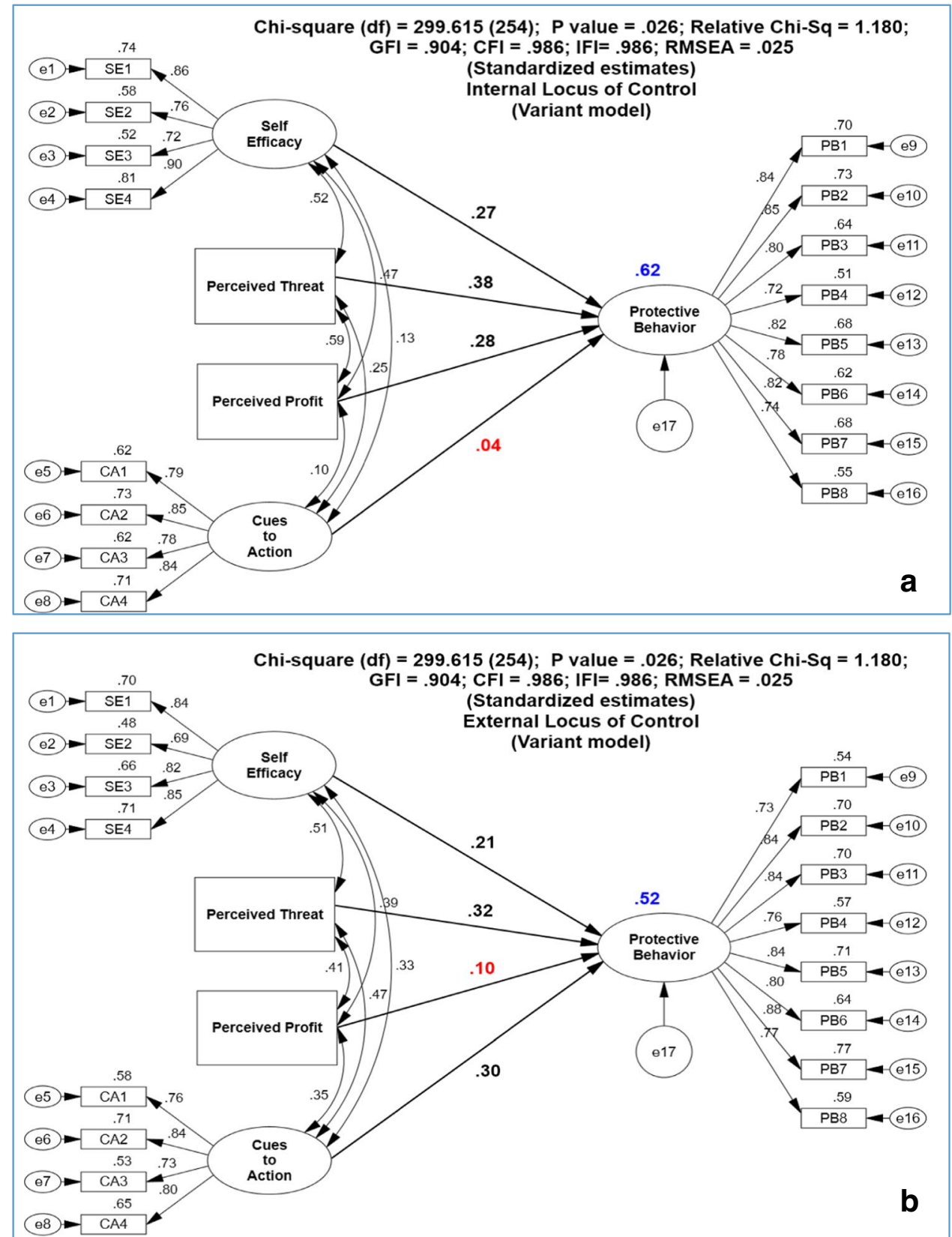

\begin{tabular}{llllllllll}
\hline Model & CMIN $\left(\chi^{2}\right)$ & DF & P & CMIN/DF & GFI & IFI Delta2 & TLI rho2 & CFI & RMSEA \\
\hline Group variant & 299.615 & 254 & .026 & 1.180 & .904 & .986 & .983 & .986 & .025 \\
Group invariant & 373.202 & 298 & .002 & 1.252 & .883 & .980 & .888 & .977 & .029
\end{tabular}

Nested model comparisons

Assuming model group variant to be correct:

$\chi^{2}$ difference (373.202-299.615=73.587); df (298-254=44); p (.003). farmers' intentions of using personal protective equipment for preventing the adverse effects of pesticide usage (Abdollahzadeh \& Sharifzadeh, 2021; Ghanbari et al., 2018; Sadeghi et al., 2014).
To test the moderating effects of internal and external locus of control, an extension to the health belief model has been conceptualized in which, perceived threat is considered as a mental belief regarding the chance of being susceptible 
Table 4 The result of hypothesized path model for higher internal or external locus of control (group variant model)

\begin{tabular}{|c|c|c|c|c|c|c|c|c|}
\hline $\begin{array}{l}\text { locus of control } \\
\text { (Moderator) }\end{array}$ & Hypothesized path & Estimate & S.E. & $\begin{array}{l}\text { Standardized } \\
\text { regression } \\
\text { weights }\end{array}$ & C.R. & $\mathrm{P}$ & $\begin{array}{l}\text { Hypothesis } \\
\text { supported }\end{array}$ & Path labels \\
\hline \multirow[t]{4}{*}{ High internal } & Self-Efficacy $\rightarrow$ Protective behavior & .216 & .062 & .272 & 3.502 & .000 & Yes & In1 \\
\hline & Perceived Threat $\rightarrow$ Protective behavior & .424 & .090 & .383 & 4.691 & .000 & Yes & In2 \\
\hline & Perceived Profit $\rightarrow$ Protective behavior & .156 & .042 & .279 & 3.682 & .000 & Yes & In3 \\
\hline & Cues to Action $\rightarrow$ Protective behavior & .052 & .087 & .038 & .601 & .548 & No & In4 \\
\hline \multirow[t]{4}{*}{ High External } & Self-Efficacy $\rightarrow$ Protective behavior & .153 & .059 & .211 & 2.609 & .009 & Yes & Ex1 \\
\hline & Perceived Threat $\rightarrow$ Protective behavior & .297 & .076 & .324 & 3.932 & .000 & Yes & Ex2 \\
\hline & Perceived Profit $\rightarrow$ Protective behavior & .049 & .034 & .102 & 1.461 & .144 & No & Ex3 \\
\hline & Cues to Action $\rightarrow$ Protective behavior & .373 & .101 & .303 & 3.687 & .000 & Yes & Ex4 \\
\hline \multicolumn{9}{|c|}{ Critical Ratios for differences between path coefficients for higher internal or external locus of control (group variant model) } \\
\hline & \multirow[t]{2}{*}{ Variable } & \multirow[t]{2}{*}{ Path Labels } & \multicolumn{3}{|c|}{$\begin{array}{l}\text { Pairwise Parameter Comparisons } \\
\text { (Variant Model) }\end{array}$} & & & \\
\hline & & & Ex1 & Ex2 & Ex3 & \multicolumn{2}{|l|}{ Ex4 } & \\
\hline & Self-Efficacy & In1 & 0.73 & & & & & \\
\hline & Perceived Threat & In2 & & -1.07 & & & & \\
\hline & Perceived Profit & In3 & & & -1.97 & & & \\
\hline & Cues to Action & In4 & & & & 2.41 & & \\
\hline
\end{tabular}

to potential danger and the severity of the perceived danger. Perceived profit is regarded as one's perception on the value of benefits and weighed against potential costs or barriers, along with self-efficacy and cues to action. The basic model explained $54 \%$ of variability of protective behavior, while the moderated model of internal locus of control clarified $62 \%$ and variant model of external locus of control elucidated $52 \%$. The results of the moderated model confirmed that the locus of control has moderate effects on the path relation between perceived profit and cues to action with protective behavior.

The perceived profit in the basic model contributed to explaining the protective behaviors. Locus of control are significantly moderated the relation of perceived profit to protective behavior, where this relationship is found to be significant for an individual with an internal locus of control and not significant for a person with an external locus of control. This means that in the mental calculations of individuals with a strong internal locus of control, the benefits outweigh the barriers and this has encouraged them to engage in more protective behaviors. While for gardeners with a higher external locus of control, the value of calculated profit is not enough to have a significant effect in encouraging them to increase their participation in protective behaviors. This result contributed to the results of past studies that had been revealed perceived benefits is a strong predictor of intention (Abdollahzadeh \& Sharifzadeh, 2021) and perceived barriers inversely related to intention and behavior (Ataei et al., 2021; Berni et al., 2021; Sapbamrer \& Thammachai, 2020).
The results of the fundamental model have shown that cues to action could increase the uptake of protective behaviors which is in the line with prior studies (Ghanbari et al., 2018; Seydi \& Rezaei, 2019). The moderated models showed that people who believe that they are in control of their health and affairs do not need much guidance for action and guidance does not play a significant role in increasing their uptake of protective behaviors. However, for those who believe that something beyond their control affects their health and affairs, the cues to action plays a significant role in protective behaviors.

The significance of the path of perceived threat on the protective behavior is displayed in the basic and two moderated model of internal and external locus of control shows the importance of this variable, although it is not moderated by any locus of control. Gardeners first feel the danger of contracting diseases related to the use of chemicals in horticulture, and then their belief in the seriousness of the risk could encourage preventive actions. These results are congruent with preceding studies that found similar susceptibility of such behaviors (Azadi et al., 2019; Ghanbari et al., 2018) and severity (Berni et al., 2021) as effective component of protective behavior.

The finding indicates that self-efficacy positively influences the protective behaviors and locus of control did not moderate this relationship. Horticulturists' trusts and beliefs in their ability to protect themselves using protective equipment raises the possibility of preventive actions which is consistent with earlier research (Ataei et al., 2021; Azadi et al., 2019; Pakmehr et al., 2021). 
Agricultural extension agents are the primary users of the results of this research. Using the results of this study, horticultural extension professionals will be enter equipped to design appropriate educational interventions to help maintain the health of gardeners whilst using chemicals, which was the main aim of this study. Consequently, the ultimate beneficiaries of the extension agent's such efforts will be the farmer's community, especially gardeners, and of course the results of this research in general can be useful for disease prevention planning within the community. In this regard, according to the results and understanding of the importance of perceived threat in explaining the protective behavior of the horticulturists with internal and external locus of control, the introduction of sensitivity and severity of risk in extension training programs is recommended. It is also suggested that the extension systems focus on introducing benefits of preventive equipment to enhance gardeners' protective behavior with an internal control source. If made are aware of the benefits of such preventative behaviors, farmers relying on their own perceived ability to control things, they then may try to take the necessary preventive measures to protect themselves against disease resulting from pesticide usage. In order to increase the level of protective behavior in individuals with a higher external locus of control, following on from this study, the suggestion is to introduce new behavioral patterns that promote the usage of preventative behaviors and will in turn create norms within the horticulturalists culture. Since normative social pressures from friends and neighbors could have more effects on behavior of individual with higher external locus of control.

A limitation of this study was the data collection stage, which was performed simultaneously with the outbreak of the COVID-19 pandemic. As a result of this, travel restrictions and social distancing implementations made it best to collect data using an online questionnaire. However, a significant number of the samples were illiterate and were not adapted to the usage of such technology. To overcome this limitation, the data was collected through face-to-face interviews, following necessary health protocols and social distancing measures.

Considering the confirmed contribution of locus of control as having a significant moderating role over the health belief model, for future studies, it is suggested that the study be repeated in different situation and communities and that other psychological variables be examined along with different socio-economic and technical barriers to investigate the uptake of protective behaviors.

Acknowledgements This research did not receive any specific grant from funding agencies in the public, commercial, or not-for-profit sectors.
Data availability The datasets generated during and/or analysed during the current study are available from the corresponding author on reasonable request.

\section{Declarations}

Ethical statement The submitted work is original and not has been published elsewhere in any form or language (partially or in full).

Consent to participate Verbal informed consent was obtained prior to the interview.

Conflicts of interest The authors declare no conflict of interest with respect to the authorship or the publication of this article.

\section{References}

Abdollahzadeh, G., \& Sharifzadeh, M. S. (2021). Predicting farmers' intention to use PPE for prevent pesticide adverse effects: An examination of the health belief model (HBM). Journal of the Saudi Society of Agricultural Sciences, 20(1), 40-47. https://doi. org/10.1016/j.jssas.2020.11.001.

Andersson, E., \& Isgren, E. (2021). Gambling in the garden: Pesticide use and risk exposure in Ugandan smallholder farming. Journal of Rural Studies, 82, 76-86.

Aniah, P., Kaunza-Nu-Dem, K. M., Dong-Uuro, P. P., Ayembilla, A. J., \& Osumanu, K. I. (2021). Vegetable farmers' knowledge on pesticides use in Northwest Ghana. Environment, Development and Sustainability, 23, 7273-7288. https://doi.org/10.1007/ s10668-020-00916-6.

Ataei, P., Gholamrezai, S., Movahedi, R., \& Aliabadi, V. (2021). An analysis of farmers' intention to use green pesticides: The application of the extended theory of planned behavior and health belief model. Journal of Rural Studies, 81, 374-384. https://doi.org/10. 1016/j.jrurstud.2020.11.003.

Azadi, Y., Yazdanpanah, M., Forozani, M., \& Mahmoodi, H. (2019). Identification of factors influencing wheat growers' adaptation behaviors under climate change conditions (case study: Kermanshah county). Geography and Development Iranaian Journal, 17(56), 39-56 [In Persian].

Bakhshayesh A. R. (2013). The relationship between personality types and general health with job satisfaction of Yazd health center staffs. Payavard, 7 (1), 42-55. [in Persian] URL:http://payavard. tums.ac.ir/article-1-5017-fa.html.

Berni, I., Menouni, A., Ghazi El, I., Duca, R.-C., Kestemont, M.-P., Godderis, L., \& EL Jaafari, S. (2021). Understanding farmers' safety behavior regarding pesticide use in Morocco. Sustainable Production and Consumption, 25, 471-483. https://doi.org/10. 1016/j.spc.2020.11.019.

Bonvoisin, T., Utyasheva, L., Knipe, D., Gunnell, D., \& Eddleston, M. (2020). Suicide by pesticide poisoning in India: A review of pesticide regulations and their impact on suicide trends. $B M C$ Public Health, 20(1), 1-16.

Borisova, E. E., Borcan, L. C., Borozan, A., Bura, M., Haratau, T., Helyer, D. \& Zota, D. (2018). Guideline for Occupational Safety \& Health practice within the agriculture sector. Publisher: Romtens Foundation 2018; ISBN: 978-973-0 281231. URL:https://www.researchgate.net/publication/331935979_Guide line_for_Occupational_Safety_Health_practice_within_the_Agric ulture_sector.

Boyd, M. J., \& Wilcox, S. (2020). Mediation analysis of the relationships between god locus of control and health behaviors in college 
students. Review of Religious Research, 62, 273-288. https://doi. org/10.1007/s13644-020-00406-1.

Bucciol, A., \& Trucchi, S. (2021). Locus of control and saving: The role of saving motives. Journal of Economic Psychology, 86, 102413. https://doi.org/10.1016/j.joep.2021.102413.

Chatripour, R., Shojaeizadeh, D., Tol, A., \& Sayehmiri, K. (2017). Determining health belief model constructs to prevent cardiovascular diseases among teachers of boys high schools in Dehloran City. SIIMU, 25 (2): 35-41, http://sjimu.medilam.ac.ir/article-12965-en.html (Persian).

Clark, M. E., Williams, R. B., Huang, J., Roth, L. D., \& Holt, L. H. (2018). A longitudinal study of religiosity, spiritual HealthLocus of control, and health behaviors in a National Sample of African Americans. Journal of Religion and Health, 57, 2258-2278. https://doi.org/10.1007/s10943-017-0548-0.

Conell-Price, L., \& Jamison, J. (2015). Predicting health behaviors with economic preferences \& locus of control. Journal of Behavioral and Experimental Economics, 54, 1-9. https://doi.org/10.1016/j. socec.2014.10.003.

Damalas, C. A., \& Abdollahzadeh, G. (2016). Farmers' use of personal protective equipment during handling of plant protection products: Determinants of implementation. Science of the Total Environment, 571. https://doi.org/10.1016/j.scitotenv.2016.07.042.

Fan, L., Niu, H., Yang, X., Qin, W., Bento, P. M. C., Ritsema, J. C., \& Geissen, V. (2015). Factors affecting farmers' behavior in pesticide use: Insights from a field study in northern China. Science of the Total Environment, 537, 360-368. https://doi.org/10.1016/j.scito tenv.2015.07.150.

Ghanbari, R., Shakarami, J., Sepahvand, F. \& Asadpouriuan, Z. (2018). Analysis of protective behavior of Khoram Abad Township farmers in pesticide use: Applying health belief model. Iranian Journal of agricultural And Development Research, 49(1), 121-133. [In Persian] URL:10.22059/IJAEDR.2017.234453.668436.

Ghiasvand Ghiasi, F., \& Ghiasvand Ghiasi, F. (2017). Analysis of factors affecting health and safety behavior of farmers (work-related complications) case study of Qazvin city. QUID: Investigación, Ciencia y Tecnología (1), 542-548.

Hair, J. F., Black, W. C., Babin, B. J., Anderson, R. E., \& Tatham, R. L. (2010). Multivariate data analysis (7th ed.). Pearson prentice hall.

Ho, R. (2006). Handbook of univariate and multivariate data analysis and interpretation with SPSS. Chapman \& Hall/CRC ,Taylor and Francis Group.

Hongjun, G., Han, W., \& Aiwu, Z. (2015). Consumers' perceived profit for online trading based on Prospect theory. The Open Cybernetics \& Systemics Journal, 9, 948-952, (https://creativecommons.org/ licenses/by/4.0/legalcode.

Kaviani, A. Roozbahani, N. \& Khorsandi, M. (2016). The assessment of the protection motivation theory Construc of skin Cancer preventive behaviors in rural women". Scientific journal of Hamadan Nursing \& Mildwifery Faculty, 24(4): 229-236. [in Persian]. https://doi.org/10.21859/nmj-24043.

Lajunena, T., \& Räsänen, M. (2004). Can social psychological models be used to promote bicycle helmet use among teenagers? A comparison of the Health Belief Model, Theory of Planned Behavior and the Locus of Control. Journal of Safety Research, 35, 115-123. https://doi.org/10.1016/j.jsr.2003.09.020.

Mehmood, Y., Arshad, M., Mahmood, N., Kachele, H., \& Kong, R. (2021). Occupational hazards, health costs, and pesticide handling practices among vegetable growers in Pakistan. Environmental Research, 200, 111340. https://doi.org/10.1016/j.envres.2021. 111340.

Mengistie, B. T., Mol, A. P., \& Oosterveer, P. (2017). Pesticide use practices among smallholder vegetable farmers in Ethiopian central Rift Valley. Springer, 19(1), 301-324. https://doi.org/10.1007/ s10668-015-9728-9.
Mirzaei, H., Shojaeizadeh, D., Tol, A., Ghasemi Ghale Ghasemi, S. \& Shirzad, M. (2017). Application of Health Belief Model (HBM) to Promote Preventive Behaviors against IronDeficiency Anemia among Female Students of High School Fereydan City: A Quasi-Experimental Study. Iranian Journal of Health Education and Health Promotion, 5(4), 260-269. [In Persian] URL: http://journal.ihepsa.ir/article-1-698-fa.html.

Moradhaseli, S., Sadighim, H. \& Ataei, P. (2017). Investigation of the farmers' safety and protective behavior to use pesticides in the farms. Health Education and Health Promotion (HEHP), 5(2), 53-65. URL: http://hehp.modares.ac.ir/article-5-8131-en. html.

Mubushar, M., Aldosari, F. O., Baig, M. B., Alotaibi, B. M., \& Khan, A. Q. (2019). Assessment of farmers on their knowledge regarding pesticide usage and biosafety. Saudi Journal of Biological Sciences, 26(7), 1903-1910. https://doi.org/10.1016/j.sjbs.2019. 03.001.

Pakmehr, S., Yazdanpanah, M., \& Baradaran, M. (2021). Explaining farmers' response to climate change-induced water stress through cognitive theory of stress: An Iranian perspective. Environment, Development and Sustainability, 23, 5776-5793. https://doi.org/ 10.1007/s10668-020-00846-3.

Pedron, S., Schmaderer, K., Murawski, M., \& Schwettmann, L. (2021). The association between childhood socioeconomic status and adult health behavior: The role of locus of control. Social Science Research, 95(102521), 1-17. https://doi.org/10.1016/j.ssres earch.2020.102521.

Ranjbar, B., Naeimi, A., \& Badsar, M. (2021). Designing an integrated model for strawberry growers' behavior toward implementation of good agricultural practices in Iran. Environment, Development and Sustainability. https://doi.org/10.1007/s10668-021-01889-w.

Richter, D., Metzing, M., Weinhardt, M., \& Schupp, J., (2013). SOEP scales manual. In: SOEP Survey Papers. No. 138, Deutsches Institut für Wirtschaftsforschung (DIW), Berlin, This Version is available at: http://hdl.handle.net/10419/85279.

Sadeghi, R., Khanjani, N., Hashemi, M., \& Movagheripour, M. (2014). Using health belief model to prevent skin cancer among farmers. Iran J Health Educ Health Promot, 2(3), 215-222.

Sapbamrer, R., \& Thammachai, A. (2020). Factors affecting use of personal protective equipment and pesticide safety practices: A systematic review. Environmental Research, 185, 109444. https:// doi.org/10.1016/j.envres.2020.109444.

Schumacker, R., \& Lomax, R. G. (2010). A beginner's guide to structural equation modeling. Routledge, Taylor \& Francis Group.

Seydi, M., \& Rezaei, R. (2019). Factors affecting farmers' safety behavior in the use of personal protective equipments in working with pesticides in Zanjan County: An application of health belief model. Iranian agricultural Extention and Education Journal, 15(2), 45-63. [in Persian]. https://doi.org/10.22034/iaeej.2019. 95290 .

Sharifzadeh, M. S., Abdollahzadeh, G., Damalas, C. A., Rezaei, R., \& Ahmadyousefi, M. (2019). Determinants of pesticide safety behavior among Iranian rice farmers. Science of the Total Environment, 651, 2953-2960.

Singh, N. S., Sharma, R., Parween, T. \& Patanjali, P. (2018). Pesticide contamination and human health risk factor. In modern age environmental problems and their remediation. Springer, p 49-68. https://doi.org/10.1007/978-3-319-64501-8_3.

Song, M., Wang, S. H., \& Sund, J. (2018). Environmental regulations, staff quality, green technology, R\&D efficiency, and profit in manufacturing. Technological Forecasting and Social Change, 133, 1-14. https://doi.org/10.1016/j.techfore.2018.04.020.

Stangier, U., Kananian, S., \& Schüller, J. (2021). Perceived vulnerability to disease, knowledge about COVID-19, and changes in preventive behavior during lockdown in a German convenience 
sample. Current Psychology, 1-9. https://doi.org/10.1007/ s12144-021-01456-6.

Tam, C. C., Li, X., Li, X., Wang, Y., \& Lin, D. (2021). Adherence to preventive behaviors among college students during COVID-19 pandemic in China: The role of health beliefs and COVID-19 stressors. Current Psychology, 1-11. https://doi.org/10.1007/ s12144-021-01942-x.

Wang, W., Jin, J., He, R., Gong, H., \& Tian, Y. (2018). Farmers' willingness to pay for health risk reductions of pesticide use in China: A contingent valuation study. International Journal of Environmental Research Public Health, 15(625), 1-10. https://doi.org/10. 3390/ijerph15040625.

Whitehead, M., Pennington, A., Orton, L., Nayak, S., Petticrew, M., Sowden, A., \& White, M. (2016). How could differences in 'control over destiny' lead to socioeconomicinequalities in health? A synthesis of theories and pathways in the living environment.
Health \& Place, 39, 51-61. https://doi.org/10.1016/j.healthplace. 2016.02.002.

Yang, X., Wang, F., Meng, L., Zhang, W., Fan, L., Geissen, V., \& Ritsema, C. J. (2014). Farmer and retailer knowledge and awareness of the risks from pesticide use: A case study in the Wei River catchment, China. Science of the Total Environment, 497, 172-179.

Publisher's Note Springer Nature remains neutral with regard to jurisdictional claims in published maps and institutional affiliations. 